\title{
A Cross Case Synthesis of the Social and Economic Development of Three Guatemalan Coffee Cooperatives
}

\author{
K. Dooley ${ }^{1}$, C. E. Dobbins², L. E. Edgar ${ }^{3}$, B. D. Borges ${ }^{4}$, S. L. Jones ${ }^{5}$, J. A. Hernandez ${ }^{6}$, A. Birnbaum ${ }^{7}$
}

\begin{abstract}
Cooperatives in the international coffee sector can help build farmer capacity, increase coffee productivity, and improve farmer welfare. The purpose of this research was to examine Guatemalan coffee cooperatives to determine unique attributes, social capital perspectives, and social impacts on small holder farmers. Four perspectives on social capital and economic development were examined across cases: (a) the communitarian view, (b) the networks view, (c) the institutional view, and (d) the synergy view. The research design was mini-ethnographic case study with cross-case synthesis. The emerging themes were (a) economic impacts, (b) multiple generation farmers, (c) capacity building trainings to improve crop management, (d) use of shade trees and organic matter for soil amendments, (e) service learning/agritourism, and (f) use of microloans to enhance economic development. Based upon the exploratory cases, each community had similar and unique internal and external interactions that could be triangulated with social capital perspectives. Networks were formed between members of the co-ops (intracommunity) giving a sense of community and purpose (i.e. agritourism, service learning) and external sources (i.e. workshops/trainings and a USAID research plot). The concept of social capital perspective gives insight into an explanation of economic development.
\end{abstract}

\section{Keywords}

Social Capital Perspectives; Impacts; Networks; International Agricultural Development

1. Kim Dooley, Professor, Texas A\&M University

600 John Kimbrough Dr., Office 240, College Station, Texas 77843-2116

k-dooley@tamu.edu, https://orcid.org/0000-0002-5654-5988

2. Catherine E. Dobbins, Ph.D. Graduate Assistant, University of Georgia

204C Four Towers, Athens, GA 30602

catherine.dobbins@uga.edu, https://orcid.org/0000-0001-5787-8752

3. Leslie D. Edgar, Associate Dean and Director, Agricultural Experiment Station, New Mexico State University Box 30003, MSC 3BF, Las Cruces, NM 88003-8003

ledgar@nmsu.edu, https://orcid.org/0000-0002-7987-8670

4. Bradley D. Borges, Senior Lecturer, Texas State University

601 University Dr., San Marcos, TX 78666

B b518@txstate.edu, https://orcid.org/0000-0002-5350-2405

5. Sarah L. Jones, University of Arkansas

1371 W Altheimer Dr., Fayetteville, AR, 72704

slj017@uark.edu, https://orcid.org/0000-0001-9569-222X

6. Jose A. Hernandez, University of Arkansas 21280 N. Kennefick Rd., Acampo, CA 95220

Jose.hernandez@ejgallo.com, https://orcid.org/0000-0002-5010-5148

7. Amanda Birnbaum, Texas A\&M University

TAMU 2133, College Station, TX 77843-2133

abirnbaum@tamu.edu, https://orcid.org/0000-0001-9425-3815 


\section{Introduction and Problem Statement}

Guatemala, despite a rich cultural tradition and vibrant history, is considered one of the poorest countries in Latin America and the Caribbean, due to unequal incomes, malnourished children, political insecurity, and a lack of skilled workers and infrastructure (cia.gov/the-worldfactbook). Many of these factors result from the destabilization of Guatemala's political structure and its agricultural sector. Around $50 \%$ of Guatemala's population resides in rural areas and relies on agriculture to meet daily needs (Aguilar-Støen, Taylor, \& Castellanos, 2016). Rural poverty and food insecurity are major issues facing Guatemala (Lopez-Riadura et al., 2019). Over $70 \%$ of those impoverished live in rural areas and rely on agriculture for their livelihood and food source. Thus, agricultural means for improved livelihoods are critical for these regions of Guatemala.

The country's location and climate make it well suited for the production of coffee. Coffee is the third largest industry in Guatemala with approximately 100,000 coffee farmers and 250 coffee cooperatives. Coffee production has transformed dramatically in Guatemala over the past two decades, mostly driven by changing tastes among international consumers for high-quality coffee (Fischer \& Victor, 2014). Previously, the coffee industry in Guatemala consisted of a few large producers, who operated fincas (plantations) producing a high-volume, low-cost, and lowquality product. Today, many former coffee laborers support their families by producing and selling coffee outside of the finca production model. These small-scale producers view coffee as an opportunity for a better life through upward social and economic mobility (Fischer \& Victor, 2014). Coffee not only represents income-generating potential, but also a way to educate their children, buy more land, and obtain greater financial security.

Studies have shown that cooperatives in the international coffee sector can build farmer capacity, increase coffee productivity, and improve farmer welfare (Ortega et al., 2019). Cooperatives and the institutions that support cooperatives help smallholder coffee farmers access alternative income sources, such as agritourism (Lyon, 2013). The International Cooperative Alliance (ICA.coop/en) defines a cooperative as a people-centered enterprise controlled by and for the members to realize a common economic, social, and cultural need in a democratic and equal way. The role of cooperatives and institutional relationships in the coffee sector cannot be underestimated, as the coffee industry is socioeconomically fragile, primarily due to the coffee rust epidemic and its impact on farmer food security, climate change, and other pests and diseases (Avelino et al., 2015). Cooperatives focus on fairness, equality, and social justice to create sustainable enterprises. However, little is known about individual co-op function within El Café Guatemalteco (ECG, pseudonym) to determine what is working across various communities and under what social capital perspective they function.

\section{Theoretical and Conceptual Framework}

In developing countries, improvement in income and welfare often depend upon generating productive employment and value-added opportunities from agricultural production. Farmers 
face higher costs, have limited access to bank loans, and are vulnerable to price fluctuations. Thus, belonging to a cooperative can provide a collective advantage to improve economic development and sustainability. However, the "performance of agrarian cooperatives strongly depends on the interaction between internal cohesion and external exchange" (Ruben \& Heras, 2012, p. 463). Agricultural cooperatives must be established based upon mutual trust and reciprocity among members. The creation of agricultural cooperatives helps smallholder producers develop economies of scale and scope (Blokland \& Gouet, 2007).

Social capital theory has been used as a theoretical framework in a variety of disciplines such as corporate governance (Kim \& Cannella, 2008), marketing (Glenane-Antoniadis, Whitwell, \& Bell, 2003), and community resilience (Aldrich \& Meyer, 2014). Diaz, Drumm, Ramirez-Johnson and Oidjarvstu (2002) used social capital theory to study economic development and food security in Peru. These authors describe the theory as "social relationships, ties and networks characterizing human social systems (p. 483). Woolcock and Narayan (2000) add to this definition with the "norms and networks that enable people to act collectively" in reference to economic development (p. 226). Woolcock and Narayan (2000) describe four perspectives on social capital and economic development: (a) the communitarian view, (b) the networks view, (c) the institutional view, and (d) the synergy view. The perspective of the communitarian view is that of local associations with community groups and voluntary organizations as the primary actors. The policy prescriptions of the communitarian view recognize social assets of the poor. In the networks view, bonding and bridging within community ties are the perspective, with actors being entrepreneurs, business groups, and information brokers. Here the policy is decentralized to create enterprise zones and bridge social divides. For the institutional view, political and legal institutions are the perspective with private and public sectors giving policy more transparency and accountability. In the synergy view, community networks and statesociety relations provide the perspective with community groups, civil society, firms, and states being the actors. In the synergy perspective, policy is focused on co-production, complementarity, participation, and linkages to enhance capacity and scale of local organizations (Wookcock \& Narayan, 2000).

\section{Purpose}

The purpose of this research was to examine three coffee cooperatives that are working with ECG to determine unique attributes, social capital perspectives, and social impacts on small holder farmers in Guatemala. The research objectives were to: (a) describe each cooperative for common and unique attributes; (b) determine unique and common characteristics across communities; and (c) analyze social capital perspectives to evaluate social impact within the communities for economic and agricultural sustainability. 


\section{Methods}

Case study is best used as a research design to illuminate decisions made within a bounded system (community) and the results or impacts of those decisions (Yin, 2018). Historically the case study design comes from the Chicago school of sociology with participant-observation as a data collection technique (Platt, 1992). Its epistemological orientation is interpretivist or naturalistic. Case study "investigates a contemporary phenomenon (the case) in depth and within its real-world context" (Yin, 2018, p. 15). The researchers specifically used the miniethnographic case study design (Fusch et al., 2017) to guide data collection in the field, which blends ethnographic and case study research designs and is beneficial when researchers are bounded by a short time in the field (specifically two weeks for this case). Ethnography is "the description and interpretation and interpretation of a culture or social group" (Holloway, Brown, \& Shipway, 2010, p. 76); however, this research design is often accompanied by extensive time and immersion within a specific cultural or social group. A mini-ethnography, by contrast, is used for a specific and narrow inquiry when time constraints exist (White, 2009). Researchers are able to understand the cultural norms, values, and roles of participants within a particular context, while limited by time constraints, due to the various methods employed with this approach. This research design uses an ethnographic approach "bounded within a case study protocol that is more feasible" for researchers with limited time and resources and thus was an appropriate design for this project (Fusch et al., 2017).

This study conducted three exploratory cases with a cross-case synthesis (Yin, 2018). Four participant observers visited three coffee cooperatives in Guatemala through a service-learning experience, each through different lenses: sustainable agriculture, crop management, motivation, and improved livelihoods. The specific methods used by the researchers included direct observation, field notes, reflective journals, informal and unstructured interviews, and participant observation (Fusch et al., 2017). The service-learning experience was designed for the researchers to extract as much observation and dialogue from each day as possible, and this was further assisted through the questioning route developed by the researchers aligning with the research questions. Each researcher conducted daily observations and conversations in the natural setting over a two-week period with field notes and narrative write-ups after each interaction. Debriefing sessions with the research team were conducted with reflective journals kept throughout the process. The NGO and three cooperatives were given pseudonyms to protect their confidentiality.

Data themes emerged through open coding from multiple sources of evidence based upon interactions with the participants and communicated through a translator. It is assumed that the translators were able to adequately communicate the views of the farmers. Each researcher created an individual case report from their data collected from individual interviews, the daily field notes, participant observations, and reflective journals. Within-case patterns were crossexamined for data triangulation. The use of participant quotations offered a deeper understanding of "a day in the life of a Guatemalan Coffee Farmer." 
The criteria used for judging the quality of the cases were (a) construct validity, (b) internal validity, (c) external validity, and (d) reliability (Yin, 2018). For construct validity, multiple sources of evidence were collected from each key informant (participant observer) who created a case from their emic perspective. Observations, informal interviews, and field notes/reflexive journals provided triangulation for data sources. For internal validity, open coding was used across the cases created by the participant observers to determine emergent themes and patterns to begin building explanations. For external validity, social capital theory perspectives were considered for each case with the use of replication logic across the three cooperatives (cross-case analyses). Reliability was ensured with maintaining a chain of evidence in an audit trail.

\section{Findings}

El Café Guatemalteco (ECG, pseudonym) is a non-profit agency that works with smallholder coffee farmer cooperatives in Guatemala to create economic opportunities that improve their quality of life. Coffee requires a great deal of processing and specialized machinery for processing. Selling unprocessed coffee (cherries) brings in much less money so the ECG coffee cooperative focused on organizing co-op farmers to produce specialty coffee and to share the cost of obtaining processing equipment. It began in 2005 after the founder had served as a volunteer in Guatemala and wanted to turn coffee production into a sustainable livelihood. The goal was for smallholder farmers to work collaboratively to improve coffee quality through better processing techniques and improving cooperative infrastructure. The NGO purchased the coffee and negotiated a fair price, offered microloans with low interest rates, and provided training and support to improve farming practices. ECG empowered farmers to process their coffee, allowing farmers to increase profits from their sales.

There are five partner co-ops with about 300 farmers currently working with ECG. This agency helps facilitate opportunities for these smallholder farmers to increase self-sufficiency and financial stability, which can lead to business growth and increased access to education, as well as assist with financial mobility for the farmers and their families. The co-ops share exporting licenses to get their coffee to United States and Canada markets. Most farmers had been working the same way with the crops before the co-op. Coffee farmers were able to sell their product for higher prices in new markets. Thus, providing them the ability to give their children an opportunity for education. As with many small-scale farming operations, family members are all engaged during the four months of the coffee harvest season. Most of the farm lands were located on the sides of volcanoes where soils were fertile but acidic. Farmers readily manage their lands with the use of organic matter to feed and amend the soils. The pruning of shade trees was done at a time where sun exposure was needed by the coffee trees, but also the debris was used to assist with the retention of moisture in the soil. Coffee trees were also pruned every 14-20 years (about 12 trees a year in rotation to ensure enough trees were fruiting for the next season) to ensure the trees were fruitful and productive. It takes about two years to begin harvesting from the same tree after heading [trimming the top back] the tree compared to three years to harvest when planted from seed. 


\section{Case One: Entre las Montañas de Fuego (EMF) (the cooperative between the volcanoes)}

This cooperative was initially persuaded by an American company to grow zucchini. After this crop failed, the farmers were hesitant to start a coffee cooperative. Initially only seven farmers agreed to participate. The first export of coffee into the United States was stopped by customs, causing further hesitation. However, the coffee cleared customs and the income generated was more than they expected. They now roast all of their coffee "in house" and have an exporting license. Currently, this coffee cooperative has 28 active members.

Most of the children in the community had some schooling, but some were returning to the community and have started a youth coffee co-op (Segunda Generación). These children have returned to the community after their education to work on their family's land or to purchase their own land through ECG loans. In addition to education, cooperative members used their income from coffee to add rooms onto homes, improve infrastructure, purchase a vehicle to transport goods, and to expand existing services. Having additional income also improved access to healthcare and the overall lifestyle with additional economic stability. A participant indicated that "... [Coffee] allowed me to have cinder block walls instead of [sugar] cane." The coffee fields are often planted on the side of the volcanoes with long walks [from their homes] required. One participant stated, "joining the coffee cooperative allowed me to purchase a truck." EMF has an extensive service-learning program (agritourism) that is coordinated through ECG. The farmers offer tours of their farm with the option to assist with agricultural work- picking coffee. They offer dinner or lunch at the farmers' homes, roasting and grinding coffee by hand, Pepian cooking (traditional Guatemalan stew made with pumpkin seeds), and textile workshops.

ECG provided low interest microloans for EMF to purchase mechanized de-pulpers, mills, a coffee roaster, and an export license. Farmers were able to purchase more land as well. One farmer in this cooperative participated in a USAID experimental plot to conduct variety and cultivar trials to determine which cultivar grows and produces best in the climate and elevation. There were three cultivars being grown (two trials, one control) and also one hybrid variety.

\section{Case Two: Boxha' (Mayan word for coffee)}

Boxha' is located in an area known for its strong Mayan cultural traditions. The community was founded with the original intent to create a seed bank of the native plants around the region to serve as a teaching tool for future generations. Coffee cultivation provided improved economic opportunities. A tropical storm hit this region and Boxha' lost 15 years of documented work with the seed bank and land conservation efforts. ECG began working with them in 2015. There are now 35 active members of the co-op, most who are second or third generation coffee farmers.

Some youth came back after their education to farm coffee, but the youth have not organized into their own co-op. One farmer had eight children, with three of them receiving degrees in 
mechanics and one returning to Boxha' to continue coffee farming and finding other ventures to increase income. Boxha' received a microloan from ECG to set up six vermicompost boxes where worms are managed to create vermicompost tea and humus, both beneficial for amending soil. Additionally, microloans assisted in the purchase of a washing/fermentation station, a de-pulping platform, and back-pack sprayers for treating leaf rust. "Financial security" and "education" were words that described the impact of joining the cooperative.

This co-op coordinated with ECG to provide service-learning experiences at the farm, including sharing meals with the farmers and women's artisan groups in a common area. This community raised rabbits for food and used the litter as part of their fertilizer. Unique characteristics of this cooperative include the highest organic matter content among soil types, growing of Pache (arabica coffee variety), including one plot that was $100 \%$ organic, and the preservation of native and culturally significant plants.

\section{Case Three: Ts'oon por el Café (TC) (Mayan word for gun [traded] for coffee)} TC members were not historically farmers; rather, their history was forged from a 30-year civil war. Members were previously guerilla fighters for equal opportunities and rights against an oppressive and abusive government who had disregard for Mayan populations. Even with many hardships, TC began to cultivate and produce coffee to provide revenue for their community after building and rebuilding from complete destruction and relocation. TC was the smallest coop and in the most remote area of the three co-ops, with eight households as active members. After many years of fighting they were able to purchase land and create a community based on coffee farming.

Most members were first-generation farmers due to the civil war. They were still learning and innovating cultural practices to figure out how to grow higher quality coffee. Therefore, most of the knowledge they had about coffee farming was through capacity trainings and workshops. Children were going to school, and some were staying in the community and learning the practices of coffee production. "Satisfaction" and "stability" were words used to describe the impact from the cooperative. One participant stated, "we traded the art of war for the art of coffee."

This co-op also gave tours of the farm and led hikes through the forest. It was at the lowest elevation which allowed them to grow a different species, Coffea canephora, known as robusta. They also grew chili peppers as a companion plant to attract birds to the red peppers, preventing the birds from eating the coffee cherries. Rather than using Grevillea robusta for shade, like the other co-ops, this co-op planted native fruit trees (avocado, mango, etc.) that provide food and shelter for native wildlife, and an additional source of income and nutrition for the community. This co-op was at a lower elevation and thus struggled with coffee leaf rust, as well as additional insect and disease pests. This co-op was the only one monitoring the insect pest population. Additionally, it has received microloans to purchase a de-pulper and build a drying patio and bodega (store) that is used for storage and co-op meetings. 


\section{Cross Case Synthesis: Explanatory Themes}

Across all three cases, cooperatives had long-term visions of sustainability for their coffee production, in terms of environmental conservation and cultivation of coffee. Next-generation farming, improvements to cultural practices, extensive use of organic matter, and the management of their lands and trees (coffee and shade) were prevalent. All farmers were aware of and showed concern for climate change and how it would affect coffee production. The themes that emerged across cases were (a) economic impacts, (b) multiple generation farmers, (c) training to improve crop management, (d) use of shade trees and organic matter for soil amendments, (e) service learning/agritourism, and (f) use of microloans to enhance economic development.

\section{Economic impacts}

In the examination of individual exploratory cases, one participant observer stated that "all farmers we met had their children in school or had given their children the opportunity for schooling and higher education (college and university)". One farmer in the case indicated that "the biggest impact coffee has had in the community was that kids did not have to drop [out of] school to help on the farms, and coffee allows them to pay for school and educate their kids." This was the overall goal of most farmers: to have their children become professionals and be able to have a career of their choosing. Another farmer stated: "... with coffee, the children can stay in school."

\section{Multiple generation farmers}

Most farmers were second or third generation farmers who have learned the cultivation practices from their fathers and grandfathers. They would like to see the "legacy" of their coffee continue for future generations.

\section{Training to improve crop management}

Most of the farmers in the co-ops improved their knowledge of coffee cultivation through trainings, workshops, previous experience working the fincas (plantations), and help from other members of the co-op. These workshops were hosted by local and international organizations that were geared toward helping small-scale farmers. In general, being a member of the co-op did not change any specific management practices in the field, but it did change their management practices in terms of becoming more business-minded.

\section{Use of shade trees and organic matter for soil amendments}

Across all cases, the use of trees to provide shade and aid in erosion control, and the incorporation of organic matter back into the soil, were prevalent. Farmers understood these practices sustain the microbiota naturally rather than overusing chemical nutrients. In comparison to the U.S. where it is typical to prepare "clean" plots for disease control, the elevation alleviates many pathogens. For example, coffee leaf rust decreases around 1,600 meters, but its pervasive presence causes farmers to continue using control for preventative reasons. Most farmers have a ratio of using 80 percent organic matter for soil amendments and only using 20 percent chemical amendments. The organic soil amendments include bi-products from the processing of coffee (coffee pulp, parchment), animal litter from chickens, horses, and 
rabbits, and organic food waste, letting little go to waste. The co-ops met to decide timing of pesticide sprays and fertilization so that label instructions were followed and no farmer would use excess chemicals that may damage the crop and environment.

\section{Service-learning/Agritourism}

All three cooperatives had incorporated agritourism and service learning as an additional source of income (one of the goals of ECG). Helping with harvesting and preparing coffee for the market, having a meal or cooking class in the community, and learning more about native plants and natural areas were common.

\section{Microloans as an Incubator for economic development}

One fundamental component to jump-start economic development was the use of microloans (also part of the mission of ECG). It was evident that communities discussed purchasing equipment, acquiring additional land, and building meeting space as things that could benefit individual families and the community. Vermicompost boxes, de-pulpers, mills, coffee roasters, back-pack sprayers, and a washing/fermentation station were examples of items purchased to improve farmer production.

The cooperative involvement holistically improved livelihoods by giving farmers a greater sense of security. Partnering with ECG increased tourism and diversified income. This case study indicated that each co-op had gone through some kind of negative experience (failed crop, natural disaster, guerrilla warfare), yet they were able to persevere and improve the human condition for their children and community. It was not evident that management practices among farmers changed dramatically after joining a co-op, but they were able to take their production to the next level. Working cooperatively and pooling their resources improved the coffee quality and prices to increase income and stability to the farmers.

\section{Social Capital Perspectives}

The basic assumption of agricultural cooperative success depends upon the interaction between internal cohesion and external exchange (Ruben \& Heras, 2012), with mutual trust and reciprocity among members. Based upon the exploratory cases, each community had similar and unique internal and external interactions that could be triangulated with social capital perspectives. For example, EMF had developed a 'next generation' co-op that was evidence of a communitarian view in regard to a 'local organization' providing social solidarity. But that alone will not lead to economic prosperity. Networks were formed between members of the co-ops (intracommunity) giving a sense of community and purpose (i.e. agritourism, service learning) and external sources (i.e. workshops/trainings and a USAID research plot). Granovetter (1995) argued that "economic development takes place through a mechanism that allows individuals to draw initially on the benefits of close community membership but that also enables them to acquire the skills and resources to participate in networks that transcend their community" (as cited by Woolcock \& Narayan, 2000, p. 232). The institutional view was not evident because the success of the co-op was not directly tied to a political, legal, or institutional environment. However, the NGO (ECG) did provide access to external markets (in a legal sense) through contracts/export licenses. Lastly, the synergy view builds upon the network 
and institutional perspectives. If the intent is to broaden the "positive manifestations of social capital-cooperation, trust, and institutional efficiency" (Woolcock \& Narayan, 2000, p. 238) then synergy was apparent in the improved livelihoods of the coffee farmers. The NGO (as an 'institution') was providing microloans to improve individual and collective infrastructure. The concept of social capital perspective gives insight into an explanation of economic development.

\section{Conclusions, Discussion, and Recommendations}

The farmers highlighted several major impacts that cooperative membership had on their livelihood. The first included increased access to education for their children. This concept was mentioned by almost every farmer interviewed in this project. Additionally, many farmers expressed that they were able to improve upon the traditional agricultural knowledge they had (from their families and from work on the fincas) though the training and capacity building facilitated by the cooperative and ECG. All farmers were affected by agritourism-an opportunity provided by their relationship with ECG. Co-op Two (Boxha') and Co-op Three (Ts'oon por el Café) emphasized that this was the major impact they experienced through their work with ECG. These two organizations indicated that their local cooperative membership assisted more in their upward economic mobility, while Co-op One (Entre las Montañas de Fuego) more heavily emphasized how ECG contributed more toward their financial gains. It agritourism (facilitated through service learning activities) was the most cited benefit for involvement with ECG with Co-op Two and Co-op Three, next to fair trade market access. Co-op One was located in the same city as ECG; thus, they had greater access to immediate resources than the other two cooperatives due to geographic location.

By viewing the economic development of the cooperatives through the lens of social capital theory, there is greater insight gained about improved farmer livelihoods through cooperative membership. Intracommunity relationships and access to external resources (human, training, market access, and agritourism) are critical factors explaining the impacts of cooperative membership with these three cases. Lyon (2013) expressed how agritourism helps strengthen cooperatives organizational capacities, which is further increased through the involvement of ECG, which Lyon's research supports by identifying the necessity of substantial external support for successful cooperative ventures. Agrotourism was an important alternative income source for Co-op Two and Co-op Three, which relates to Lyon's (2013) finding that “alternative income sources are especially critical for small and medium scale farmers in countries [...] such as Guatemala" (p. 188). The three cooperatives detailed the various ways through which ECG benefitted them; however, the researchers noted that increased geographical separation between ECG and each cooperative diluted the amount of success attributed to involvement with ECG. Other cooperatives working with variously located cooperatives or communities should examine their impacts based on geographic location of their clients to better serve all who rely on their services. 
The mini-ethnographic case study design enabled the researchers to conduct a cross-case analysis that examined the experiences of three cooperatives working with a local agency focused on improving smallholder coffee farmers' livelihoods through economic development. These results were shared with the staff of ECG to give an external perspective to the work ECG does in country. This research process was facilitated through a service-learning experience which enabled the researchers to seamlessly integrate the necessary methods for the miniethnographic case study due to the existing infrastructure in place by the design of the servicelearning component. The implications of these results for practice include using the miniethnographic case study design to conduct rigorous, in-depth research with communities with whom researchers only have a limited amount of time, constrained by the service-learning experience being only two weeks long. This research design allows for rapport to be built quickly through participant observation and the conversational nature of informal, unstructured interviews. At the end of the service-learning experience, the researchers were able to present ECG with evidence-based results about the work they do and how each cooperative interprets and shares their experiences with the agency. This evidence-based practice is a way to disseminate research findings to the stakeholders in a comprehensive and easily understandable way. Future research should be conducted with ECG with similar methods as they experience a change in leadership. Other researchers in international settings with a limited time frame are encouraged to embrace the use of the mini-ethnographic case study to extract the most meaning, interpretation, and evidence from their experience as possible.

\section{References}

Aguilar-Støen, M., Taylor, M., \& Castellanos, E. (2016). Agriculture, land tenure, and international migration in rural Guatemala. Journal of Agrarian Change, 16(1), 123-144. https://doi.org/10.1111/joac.12091

Aldrich, D. P., \& Meyer, M. A. (2015). Social capital and community resilience. American Behavioral Scientist, 59(2), 254-269. https://doi.org/10.1177/0002764214550299

Avelino, J., Cristancho, M., Georgiou, S., Imbach, P., Aguilar, L., Bornemann, G., Läderach, P., Anzueto, F., Hruska, A. J., \& Morales, C. (2015). The coffee rust crises in Colombia and Central America (2008-2013): Impacts, plausible causes and proposed solutions. Food Security, 7, 303-321. https://doi.org/10.1007/s12571-015-0446-9

Blockland, K., \& Gouet, C. (2007). Peer-to-peer farmer support for economic development. In Producer Organization and Market Chains. Wageningen, The Netherlands: Wageningen Academic Publishers. 
Central Intelligence Agency (2019). World factbook. Retrieved from https://www.cia.gov/library/publications/resources/the-worldfactbook/attachments/summaries/GT-summary.pdf

Diaz, H. L, Drumm, R. D., Ramirez-Johnson, J. \& Oidjarv, H. (2002). Social capital, economic development and food security in Peru's mountain region. International Social Work, 45(4), 481-495.

Fischer, E. F., \& Victor, B. (2014). High-end coffee and smallholding growers in Guatemala. Latin American Research Review, 49(1), 155-177.

Fusch, P. I., Fusch, G. E., \& Ness, L. R. (2017). How to conduct a mini-ethnographic case study: A guide for novice researchers. The Qualitative Report, 22(3), 923-941.

Glenane-Antoniadis, A., Whitwell, G., Bell, S. J., \& Menguc, B. (2003). Extending the vision of social marketing through social capital theory: Marketing in the context of intricate exchange and market failure. Marketing Theory, 3(3), 323343. https://doi.org/10.1177/147059310333002

Holloway, I., Brown, L., \& Shipway, R. (2010). Meaning not measurement: Using ethnography to bring a deeper understanding to the participant experience of festivals and events. International Journal of Event and Festival Management, 1(1), 74-85. https://doi.org/10.1108/17852951011029315

International Co-operative Alliance (2019). Retrieved from https://www.ica.coop/en.

Lopez-Riadura, S., Barba-Escoto, L., Reyna, C., Hellin, J., Gerard, B., \& van Wijk, M. (2019). Food security and agriculture in the Western Highlands of Guatemala. Food Security, 11(4), 817-833. https://doi.org/10.1007/s12571-019-00940-z

Lyon, S. (2013). Coffee tourism and community development in Guatemala. Human Organization, 72(3), 188-198.

Ortega, D., Bro, A., Clay, D., Lopez, M., Tuyisenge, E., Church, R., \& Bizoza, A. (2019). Cooperative membership and coffee productivity in Rwanda's specialty coffee sector. Food Security, 11(4), 967-979.

Social Capital Perspectives; Impacts; Networks; International Agricultural Development https://doi.org/10.1007/s12571-019-00952-9

Ruben, R., \& Heras, J. (2012). Social capital, governance and performance of Ethiopian coffee cooperatives. Annals of Public and Cooperative Economics, 83(4), 463-484. 
White, K. L. (2009). Meztizaje and remembering in Afro-Mexican communities of the Costa Chica: Implications for archival education in Mexico. Archival Science, 9, 43-55. https://doi.org/10.1007/s10502-009-9102-5

Woolcock, M., \& Narayan, D. (2000). Social capital: Implications for development theory, research, and policy. The World Bank Research Observer, 15(2), 225-249.

Yangmin, K., \& Cannella, A. A. (2008). Toward a social capital theory of director selection. Corporate Governance, 16(4), 282-293.

Yin, R. K. (2018). Case study research and applications: Design and methods. Los Angeles, CA: Sage.

(C) 2020 by authors. This article is an open access article distributed under the terms and conditions of the Creative Commons Attribution license (http://creativecommons.org/licenses/by/4.0/). 